\title{
Trait Persistence Moderates the Association between Gender and Change in Smoking Urge Across Repeated Cue Exposure Trials
}

\author{
Bradley N. Collins, ${ }^{1}$ Uma S. Nair, ${ }^{2}$ Eugene Komaroff, ${ }^{3}$ Maria Karekla, ${ }^{4}$ Georgia Panayiotou, ${ }^{4}$ \\ Sean McCormick, ${ }^{1}$ and Samantha Davis ${ }^{1}$ \\ ${ }^{1}$ Health Behavior Research Clinic, Department of Social and Behavioral Sciences, College of Public Health, Temple University, \\ Philadelphia, PA \\ 2 Department of Health Promotion Sciences, College of Public Health, University of Arizona, Tucson, AZ \\ 3 Graduate School, Keiser University, Ft Lauderdale, FL \\ ${ }^{4}$ Department of Psychology, University of Cyprus, Nicosia, Cyprus
}

\begin{abstract}
revious research suggests that persistence, an individual difference characteristic representing the ability and willingness to maintain engagement in challenging or aversive contexts, may relate to smoking relapse. Improving understanding of the persistence-relapse risk association could guide improvements in behavioural interventions. We explored whether persistence and gender related to change in smoking urges across multiple cue exposure trials (an analogue of extinction learning and relapse risk). Participants included abstinent smokers who completed 12 massed, 5-minute smoking cue exposure trials using guided imagery as well as olfactory, tactile, visual and motor cues associated with smoking. We used multilevel logistic growth curve modelling to explore predictor associations with change in urge. Results suggested that gender related to urge whereby males showed greater initial and sustained reactivity than females. Persistence was not associated with female urge trajectories. However, compared to males with high persistence, males with low persistence evidenced sustained urge reactivity over time. Results suggest that greater persistence relates to reduction of conditioned responding (e.g., urges) among abstinent male smokers when exposure trials include complex cues most closely related to nicotine self-administration. Because persistence is modifiable, males with low persistence may benefit from interventions that include elements designed to increase persistence in urge eliciting situations.
\end{abstract}

\section{Introduction}

Improving tobacco dependence interventions remains a global public health priority (World Health Organization, 2015). The most effective tobacco interventions use a combination of pharmacotherapy and behavioural components to mitigate withdrawal symptoms, boost motivation to quit and facilitate coping skills. High rates of relapse following smokers' cessation attempts continue to push researchers to test innovative treatment strategies. Recent behavioural intervention trials reveal a resurgent interest in cue exposure strategies (Germeroth et al., 2017; Xue et al., 2017). Interventionists consider cue exposure strategies to facilitate extinction learning during cessation treatment. Extinction is observed as the weakening of one's conditioned response (e.g., smoking urge) over time following repeated exposures to conditioned stimuli, or cues (e.g., smoking paraphernalia) across non-reinforced contexts (situations in which a smoker avoids or is prevented from self-administering nicotine and experiencing drug-related reinforcement).

The theoretical and empirical basis for utilising cue exposure treatment (CET) methods for smoking cessation centres on evidence that (a) cue-elicited reactivity (e.g., elevated urge) relates to relapse risk (e.g., Payne, Smith, Adams, \& Diefenbach, 2006; Waters et al., 2004) and (b) CET facilitates extinction of cue reactivity (e.g., Collins \& Brandon, 2002; Collins, Nair \& Komaroff, 2011). Similarly, Lam et al., 2012 showed that elevated negative affect following smoking cue exposure was associated with greater risk for smoking relapse

Address for correspondence: Bradley N. Collins, Health Behavior Research Clinic, Department of Social and Behavioral Sciences, College of Public Health, Temple University, Philadelphia, PA. Email: collinsb@temple.edu 
(Lam et al., 2012). CET trials have also demonstrated the potential utility of cue exposure in promoting longer periods of abstinence compared to standard control or relaxation (Drummond \& Glautier, 1994; Hartwell et al., 2016; O'Connell, Shiffman, \& DeCarlo, 2011).

Cue-elicited urges/cravings to smoke continue to be considered key factors related to continued smoking, (Tiffany \& Wray, 2009) difficulty initiating a quit attempt (Orleans, Rimer, Cristinzio, Keintz, \& Fleisher, 1991) and difficulty maintaining abstinence after quitting (Bagot, Heishman, \& Moolchan, 2007; Shiffman, 1991; Tiffany, 1990; Wray, Gass, \& Tiffany, 2013), even though smoking can occur in the absence of antecedent urges to smoke (Tiffany, 1990). Research on the association between smoking cue reactivity and relapse is mixed, and evidence exists that some smokers do not respond to CET (Perkins, 2012; Wray et al., 2013). However, these mixed results could be attributed in part to the wide range of cross-study exposure methods (e.g., guided imagery; visual slide presentation of cues; actual drug paraphernalia) and reactivity measures (e.g., self-reported urge, negative affect, heart rate) as well as to evidence that individual differences exist across smokers' conditioning histories. These individual differences influence the degree to which a smoker may respond to specific individual cues or complex contextual cues (Collins et al., 2010; Perkins, 2009; Shadel et al., 1998; Unrod et al., 2014). Moreover, there may exist a number of contexts and individual difference moderators that influence variability in urge response and whether urges lead to relapse or interfere with completion of substance dependence treatment (Collins \& Brandon, 2002; Kavanagh, Andrade, \& May, 2005). Therefore, more research is needed to better understand the potential influence of individual difference characteristics, behavioural repertoires, or 'traits', that may contribute to variability in response to cue exposure procedures and CET outcomes.

We assert that persistence is a behavioural repertoire that could relate not only to one's response to CET procedures, but also to one's ability to maintain abstinence and manage cue-elicited reactivity (e.g., urges) after a quit attempt. Operationalised in Clonginger's theory of personality (Cloninger, Svrakic, \& Przybeck, 1993) and the theory of learned industriousness (Eisenberger, Michael Kuhlman, \& Cotterell, 1992), persistence can be described as a relatively stable, but modifiable trait observed as the ability to maintain goal-directed effort in contexts that present mental or physical demands, or that elicit frustration or fatigue. During CET, individuals with higher trait persistence compared to those with lower persistence may respond more favourably to the demands of exposure procedures and unpleasant experience of conditioned reactivity, thereby increasing the likelihood of extinction learning.

The basis for this assertion is grounded in theory: Compared to individuals with a history of reinforcement for low effort in aversive contexts (e.g., challenging tasks and unpleasant situations), learned industriousness theory posits that individuals rewarded for high effort in aversive contexts are more likely in the future to persist in those contexts and experience their effort as less aversive over time. Smokers attempting to quit must exert high effort to avoid smoking while tolerating unpleasant nicotine withdrawal or during situations that elicit urges to smoke. Thus, greater persistence in maintaining abstinence when experiencing withdrawal or strong urges may facilitate extinction learning and, in turn, reduce relapse risk (Quinn, Brandon, \& Copeland, 1996).

More recent studies show that persistence is associated with longer abstinence after a quit attempt in both retrospective (Brown, Lejuez, Kahler, \& Strong, 2002; Steinberg, Williams, Gandhi, Foulds, \& Brandon, 2010) and prospective smoking intervention studies controlling for other factors associated with relapse (Brandon et al., 2003). However, despite growing evidence of the predictive validity of persistence in smoking intervention research (Steinberg et al., 2012), results across studies show varying strengths of association between persistence and long-term smoking cessation outcomes (e.g., Brown et al., 2009; Etter, 2010; Kalman, Hoskinson, Sambamoorthi, \& Garvey, 2010). This inconsistency may be attributed, in part, to the differential use of self-report vs. behavioural task measures of persistence. Within Cloninger's typology and self-report measurement, persistence may represent one's cognitive appraisal of their ability to maintain engagement in aversive contexts. Alternatively, behavioural measures of persistence that require effortful performance with a challenging task appear to additionally capture variability in individuals' emotional experience (e.g., frustration) arising from task demands. These observations have lead some researchers to consider that behavioural measures of persistence overlap with the construct of distress tolerance (Brandon, Vidrine, \& Litvin, 2007; Karekla, Champi, Panayiotou, \& Collins, 2015; Steinberg et al., 2010). Thus, inconsistencies across selfreport and behavioural studies may reflect what Kalman and colleagues (2010) suggest is the measurement of related, but different constructs: the construct of trait persistence as measured via self-report and the more emotion-based construct, distress tolerance, observed in behavioural tasks and characterised as one's perceived ability to endure distress during effort (Leyro et al., 2010).

Despite previous inconsistencies between measures of persistence in predicting long-term cessation outcomes, there is growing evidence that trait-type persistence may be associated with decreased urges in both smokers and individuals with other addictions. For example, Zilberman, Tavares, \& El-Guebaly (2003) found that among treatment seeking women with substance-related disorders, greater persistence was associated with less craving. Etter's (2010) results suggest that, compared to current smokers, persistence is higher among former smokers who have achieved long-term abstinence perhaps 
because ex-smokers have had greater opportunity for reinforcement of their efforts to maintain abstinence across multiple urge-eliciting contexts. More recent studies expand evidence of the persistence-urge link: Panayiotou and colleagues (Karekla et al., 2015; Panayiotou, Karekla, Champi, \& Collins, 2014) demonstrated that smokers reported greater urge reactivity following sustained effort with a stress inducing task (PASAT; Lejuez, Kahler, \& Brown, 2003). Reactivity was mediated by increased negative affect during the task, and moderated by gender, such that increased negative affect appeared to be a more important catalyst to smoking urge among men compared to women.

Based on theory and collective evidence, persistence may be an important individual difference characteristic that differentiates smokers' ability to tolerate urge-related consequences of abstinence. Therefore, persistence may be a relevant factor contributing to extinction learning, and help explain why some smokers experience habituation or extinction of cue reactivity more quickly than others in urge-eliciting situations during abstinence.

\section{Aims}

The goal of our study was to explore the association between abstinent smokers' self-reported, trait-like persistence and urge reactivity across repeated cue exposure trials. The cue exposure procedures served as an analogue of a high relapse-risk, urge-eliciting situation with common smoking cues present. This study represents a secondary analysis of data from a previous study examining the role of negative affect on cue reactivity (Collins, Nair, \& Komaroff, 2011) which demonstrated a gender $\times$ time interaction with males reacting with significantly greater initial and sustained urge compared to women - results consistent with evidence of the moderating effect of gender on smoking cue reactivity (e.g., Perkins, Epstein, Grobe, \& Fonte, 1994). Given this evidence, the present study tested the hypothesis that low persistence would relate to greater sustained urges over time (resistance to urge extinction) and that within our cue exposure paradigm, the effect of persistence would be greater among men than women.

\section{Methods}

All procedures were approved by the institutional review board. The overarching design and methods for this study followed the parent study (Collins, Nair, \& Komaroff, 2010). We recruited participants using print advertisements. Male and female current smokers and recent quitters with 6-12 months of abstinence were recruited to pilot test procedures and explore gender differences in urge reactivity across repeated trials. Participants were eligible if they were over 18-years old and had smoked more than 10 cigarettes daily. Ineligible participants reported a history of cardiac or pulmonary disease, current severe psychopathology (e.g., psychotic disorders), or current use of other tobacco products, nicotine replacement therapy, or psychotropic medication. Participants were instructed to maintain abstinence overnight and eat breakfast prior to their morning session and were excluded if pre-session $\mathrm{CO}$ was greater than $10 \mathrm{ppm}$. After completing informed consent, current smokers (not ex-smokers) were provided with $14 \mathrm{mg}$ patch, thereby increasing the opportunity for observing conditioned urge responding not attributed to nicotine withdrawal. All participants waited in a lounge for 45 minutes to complete baseline assessments prior to cue exposure procedures described next.

\section{Cue Exposure}

Participants sat in a comfortable chair for procedural overview: the experimenter showed participants a partitioned, remote-controlled turntable used for cue presentation, describing that cues could include common objects (e.g., pen and paper) or smoking-related objects. Participants learned that audio instructions would guide them to use the objects and demonstrated how to light a cigarette without putting it in their lips. They were told that smoking was not permitted and that the experimenter would monitor their adherence during the session and test their $\mathrm{CO}$ after the session to verify sustained abstinence.

To habituate to the setting, participants completed a 15-minute resting baseline trial. Before each subsequent exposure trial, the experimenter set up the turntable and, 60 seconds later from the observation room, remotely rotated it to present cues while starting the audio instructions. The first minute of instructions guided participants to imagine using the items on the turn table. The remaining 4 minutes guided the participant to handle the objects and attend to specific features of the objects. Urge measures were obtained at the end of each trial.

For the first two exposure trials, participants were presented with neutral cues (paper and pencil) or smoking cues (a pack of the participant's brand of cigarettes, lighter, ashtray) in counterbalanced order. After these trials, the experimenter led participants to the research suite where they were invited to use the bathroom and instructed to drink one ounce of water. Participants then returned to the testing room to complete the remaining 5 -minute trials. There were 12 total, consecutive smoking cue exposure trials using identical structure, timing, and materials. Participants imagined smoking, then were instructed to engage in a series of motor behaviours associated with smoking after lighting the cigarette while attending to the sight, smell, and tactile sensations related to the cigarette and smoke. After the fourth smoking cue trial, participants received a 30-minute break in the lounge with a standardised snack and one ounce of water. After the eighth trial, participants had a 5-minute stretch break with one ounce of water. At the conclusion of the last exposure trial, participants were debriefed and study compensation was offered. 


\section{Measures}

Baseline assessments included questions related to participant characteristics and smoking history. All measures were chosen based on their psychometric strengths with a preference for shorter measures to reduce participant response burden.

Dependent variable: Self-reported urge to smoke was assessed as a repeated measure after each exposure trial using a single item on a 10 -point Likert scale $(0=$ no urge at all to $9=$ very strong urge). A single item scale was used to minimise participant burden across repeated exposure trials. Single item scales, including visual analogue scales are valid methods for assessing self-reported smoking urge (Ussher, Beard, Abikoye, Hajek, \& West, 2013; West \& Ussher, 2010). To address convergence and interpretational difficulties that occurred using urge as a continuous dependent variable, urge was dichotomised at the median and modelled as a binary random variable with predicted values plotted as lines across trials.

Independent variable: Persistence was assessed at baseline using the five-item persistence dimension of the temperament personality questionnaire (a subset of the temperament and character inventory - version 9) (Cloninger, Przybeck, \& Svrakic, 1991; Cloninger, Przybeck, Svrakic, \& Wetzel, 1994). The scale is derived from Cloninger's neuro-psychological theory of personality traits which includes four inheritable dimensions of temperament: novelty seeking, harm avoidance, reward dependence and persistence (Cloninger et al., 1993). Internal consistency of this scale with this sample $(\alpha=$ 0.725 ) suggested acceptable reliability.

Controlling covariates: Negative affect was assessed using the 20-item positive and negative affect schedule (PANAS; Watson, Clark, \& Tellegen, 1988b). Items are scored on a five-point Likert scale ( $1=$ very slightly or not at all to $5=$ extremely). Both positive and negative affect scales are internally consistent and demonstrate good convergent and discriminant validity (Crawford \& Henry, 2004; Watson, Clark, \& Tellegen, 1988a). Nicotine withdrawal symptoms ratings were obtained using the Minnesota Withdrawal Symptom Checklist (WSC; Cappelleri et al., 2005; Hughes \& Hatsukami, 1986) along with eight additional items that assessed physical symptoms. Items were rated on a four-point scale from 'not present' to 'severe'. For the purpose of this study, we examined withdrawal-related symptoms other than urge, including 'other physical symptoms' (e.g., sweating, nausea), 'energy' (e.g., drowsiness, fatigue), and 'hunger'. Smoking status differentiated between participants who enrolled as current smokers agreeing to be abstinent during procedures vs. recent quitters. Baseline smoking urge was assessed prior to the first smoking cue exposure trial.

\section{Analysis}

The sample size was too small to compare group differences between abstinent current smokers and recent quitters. The entire sample was used to facilitate power to test the study hypothesis. To characterise differences in urge that could be attributed to gender and persistence across trials, multilevel logistic growth curve models (Raudenbush \& Bryk, 2002) were developed with PROC GLIMMIX in SAS v9.2 (Littel, Stroup, Milliken, Wolfinger, \& Schabenberger, 2006). Because our previous analysis demonstrated significant effects of gender and time (and gender by negative affect by time) on smoking urge across trials (Collins, Nair, \& Komaroff, 2011), this analysis tested whether the probability of 'above average urge' (urge $>2$ in this sample) could be modelled with an interaction by time, gender and persistence, after adjusting for baseline urge, smoking status and negative affect. Time was parameterised as an ordinal variable corresponding to trials. To model the theoretically predicted initial increase and subsequent decrease in urge, time was entered as a second-order polynomial. Baseline urge was group centred at the mean and included in the model to equate for any inter-individual differences in initial urge. Negative affect, defined as each subject's mean score on the PANAS across all data collection points, was dichotomised at the median and entered in the model as an indicator $(0 / 1)$ covariate. The same approach was used for persistence with a median split to characterise high or low persistence. The initial steps involved in building the models are detailed previously (Collins et al., 2011). Based on those previous results, we entered gender as a main effect as well as an interaction effect with linear and quadratic time. To determine if persistence moderated gender effects in initial trajectories (increase) of urge as well as later trajectories (decrease/extinction effect), persistence by gender was entered as an interaction with the linear and quadratic terms for time after adjusting for baseline urge, smoking status and negative affect.

\section{Results/Findings}

Forty-three participants, including thirty-three abstinent current smokers and ten recent quitters, completed the massed extinction trial session. One eligible smoker was not included in the analyses because of voluntarily withdrawing from the study after Trial 4. The final sample included 51\% male, 54\% African American, and 51\% unemployed participants with a mean age of $49 \pm 11$ years old. Participants smoked for an average of 20.56 \pm 10.83 years, and had a mean, baseline negative affect score of $17.44 \pm 5.96$. There were no significant differences between males and females on smoking status, psychosocial, or demographic variables except that males, on average, were older than females $(t=2.56, p<0.02)$. There was no change in total WSC scores between the first and last smoking cue exposure trials. Table 1 displays mean age, cigarettes smoked per day (prior to cessation in the ex-smoker group) and percentage of ex-smokers and abstinent current smokers. There were no significant 
Table 1

Baseline age, cigarettes smoked, and smoking status by gender and persistence

\begin{tabular}{llllll}
\hline & \multicolumn{2}{c}{ Men } & & \multicolumn{2}{c}{ Women } \\
\cline { 2 - 3 } \cline { 5 - 6 } & High persistence & Low persistence & & High persistence & Low persistence \\
\hline Age & $46.45(7.17)$ & $46.0(8.7)$ & & $36.4(9.0)$ & $43.8(13.5)$ \\
Cigarettes smoked/day & $16.5(13.3)$ & $13.9(8.9)$ & & $11.7(11.4)$ & $11.4(8.9)$ \\
Smoking status & & & & \\
Ex-smoker & $30 \%(n=3)$ & $10 \%(n=1)$ & & $40 \%(n=4)$ & $20 \%(n=2)$ \\
Current smoker & $24.2 \%(n=8)$ & $24.2 \%(n=8)$ & $36.4 \%(n=12)$ & $15.2 \%(n=5)$ \\
\hline
\end{tabular}

Table 2

Gender $\times$ persistence effects on change in urge trajectory across massed trials: Logistic growth curve modelling variance components

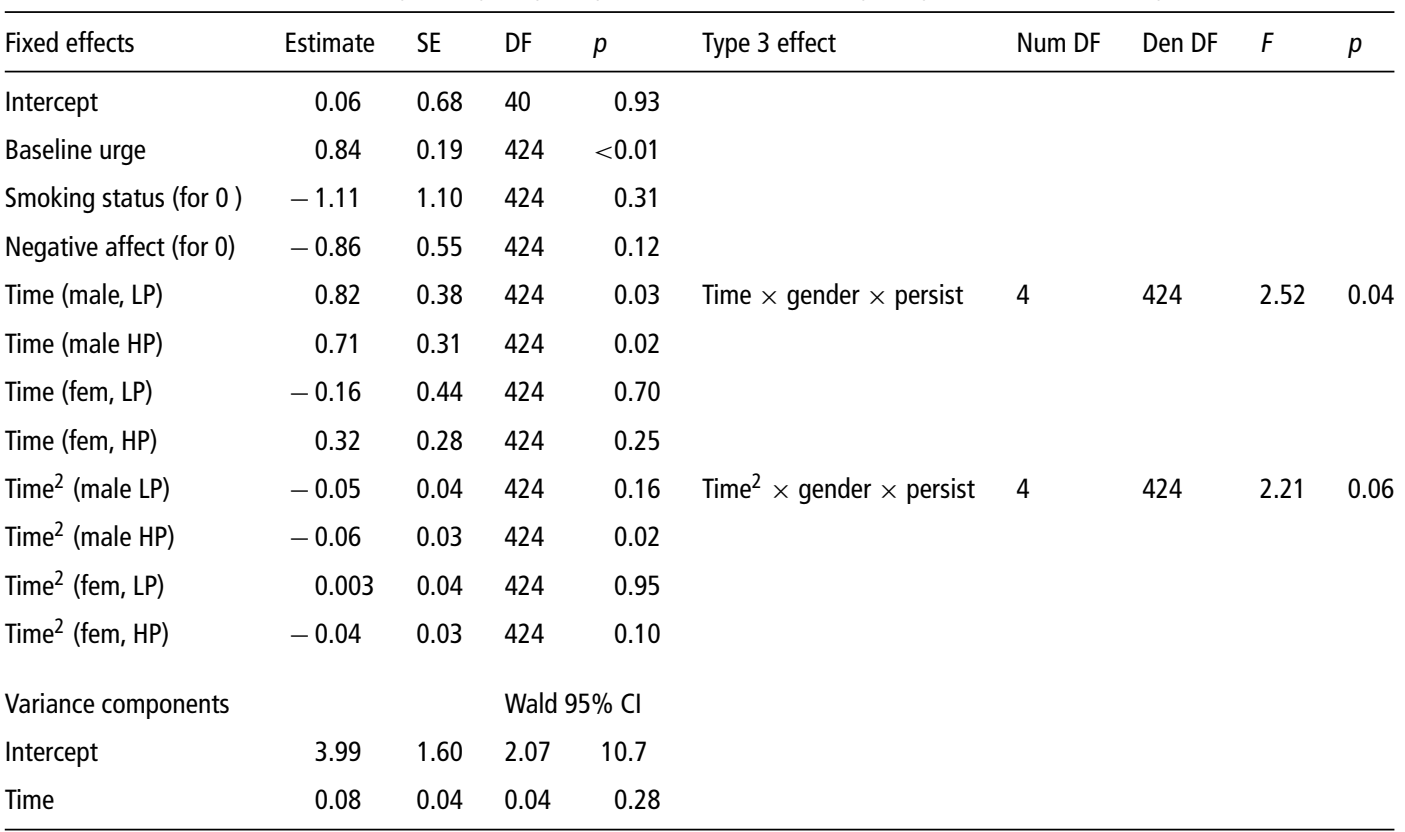

differences in these characteristics across the four subgroups of participants.

In Table 2, 'fixed effects' represent overall beta coefficients and 'variance components' represent the variation (and covariation) in the random effects. Examination of the random effects revealed an extremely wide 95\% confidence interval for the quadratic random effect $(0.000397$ to $31,082,743)$, thus was eliminated from the model. The final model demonstrates a significant persistence $\times$ gender $\times$ time interaction in the linear trajectories representing the initial increase in reactivity $(p=$ 0.041 ) with a three-way quadratic interaction, representing change in reactivity trajectory, that approaches significance $(p=0.067)$ (see Table 2).

The individual slopes in the table and Figure 1 reveal that female trajectories were relatively flat (did not change with time or persistence), whereas the males had a significantly steeper linear effect corresponding to increasing urge. Moreover, males with high persistence demon-

\section{Table 3}

Mean urge at peak reactivity and last extinction trial (Gender $\times$ persistence)

\begin{tabular}{lllc}
\hline & Peak urge & Last trial urge & $\begin{array}{l}\text { Mean } \\
\text { difference }\end{array}$ \\
\hline Males: low persistence & $5.11(2.71)$ & $4.40(2.33)$ & 0.71 \\
Males: high persistence & $4.20(3.22)$ & $3.90(3.14)$ & 0.30 \\
Females: low persistence & $2.28(3.20)$ & $2.30(3.59)$ & -0.02 \\
Females: high persistence & $2.31(2.65)$ & $2.50(3.12)$ & -0.19 \\
\hline
\end{tabular}

Note: Peak urge is the highest mean urge midway through exposure procedures (T4-6).

strated extinction in urge response (reduction in cue reactivity) compared to males with low on persistence, who demonstrated sustained smoking urge across trials. Table 3 further illustrates the group differences in urge by showing the mean peak urge by group midway through procedures and on the last trial. These data illustrate the 
Urge by Gender Modified by Persistence

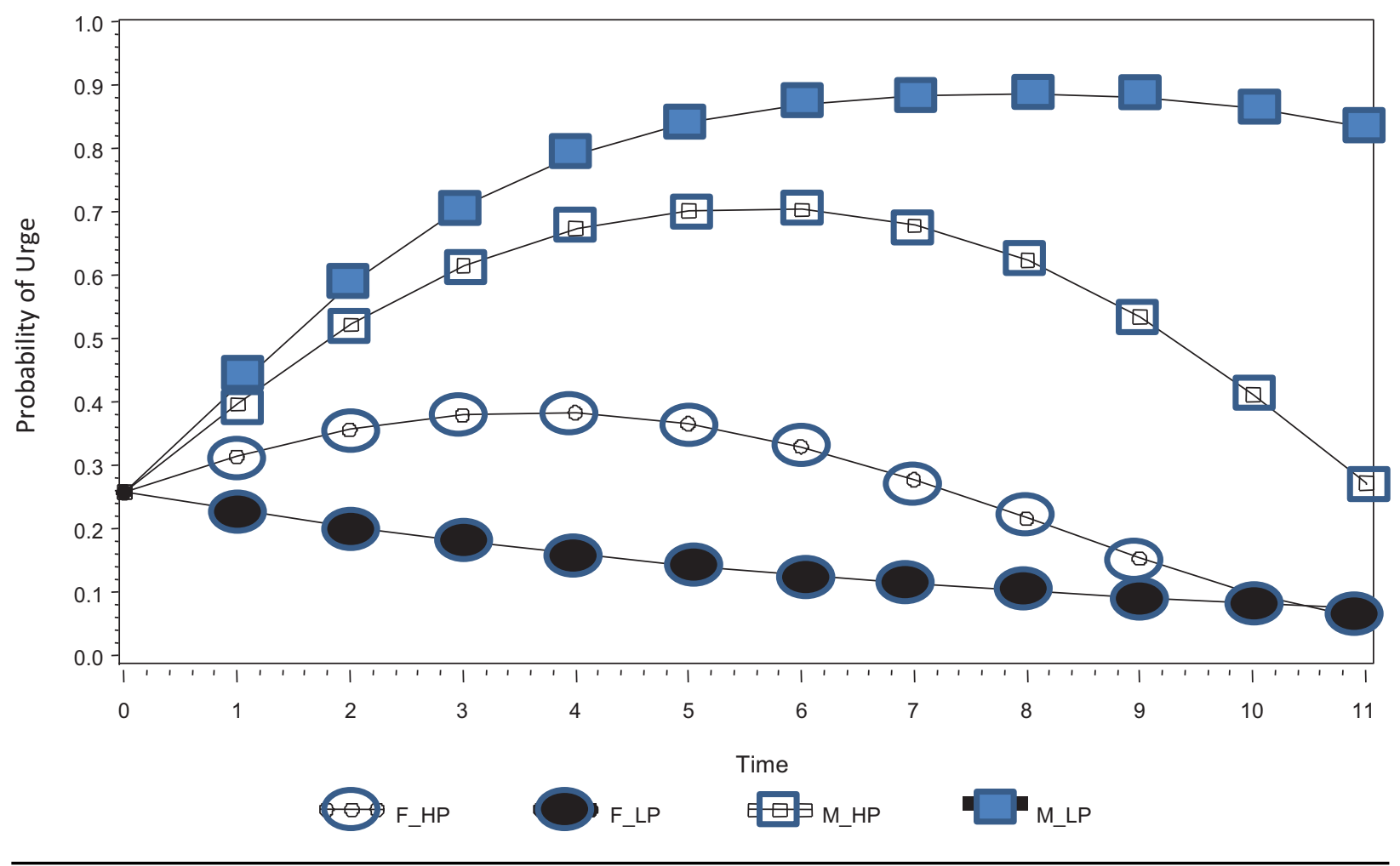

Figure 1

Probability of above average urge across cue exposure trials.

Note: $\mathrm{F}=$ female; $\mathrm{m}=$ male; $\mathrm{HP}=$ high persistence; $\mathrm{LP}=$ low persistence

gender difference, and the greater sustained urge reactivity among the low-persistence males vs. high-persistence males.

\section{Conclusions}

This study is the first to demonstrate the relation of persistence to the change in smoking cue reactivity (urge to smoke) across massed exposure trials. These results add to growing evidence that individual difference characteristics may influence smoking cue reactivity, and they expand our understanding of how persistence may relate to cue reactivity during abstinence. These results could inform future clinical trials and interventions that use cue exposure methods to promote extinction learning.

In this study, the gender by persistence interaction over time bears out a persistence-urge association among men, not women, when participants are exposed to a context that includes smoking cues proximally associated with nicotine self-administration. Specifically, this context presented smoking paraphernalia, the sight and smell of tobacco and smoke, branding from participants' preferred cigarettes, and motor behaviours mimicking smoking. Abstinent male smokers with higher persistence trait scores demonstrated an initial increase in cue reactivity followed by extinction (reduction in urge). In contrast, men reporting lower persistence demonstrated greater, sustained urge reactivity during the session, sug- gesting they may be at greater risk for relapse in similar high-risk contexts. Given the potential for trait-like persistence to generalise across contexts, male smokers with low persistence who are attempting to quit smoking, may experience greater, sustained urge across contexts in which they are exposed to cigarette paraphernalia, tobacco smoke and other cues proximally related to nicotine self-administration.

In contrast to males, there was no difference in reactivity or subsequent extinction trajectories among women that related to persistence. In part, this outcome could be attributed to the overall low urge reactivity observed among female participants using this study's exposure procedures. Similar relative non-responsiveness of subsamples to exposure procedures is evident in CET approaches targeting other dependence disorders, and may suggest that the cue complex was not sufficiently salient to the subsample of female smokers. The lower reactivity of females relative to males in this study parallels other research demonstrating that women experience less reinforcement from nicotine than men (Perkins, Donny, \& Caggiula, 1999). Indeed, other studies have demonstrated that gender may moderate reductions in urge elicited by negative affect (not smoking cues) (Unrod et al., 2014). Perhaps, a cue exposure paradigm that is more salient to women may elicit adequate variability in urge reactivity needed to test the 
persistence hypothesis in women. Future research could consider using urge-eliciting contexts that include social cues or negative affect cues to test this hypothesis with female smokers.

Our results suggest treatment implications. Identifying individuals with low persistence could improve tailoring of behavioural strategies that shape persistence or provide more intensive coping skills training for those individuals. Early studies on persistence point to this implication, wherein training individuals to persist in high effort tasks could generalise to other behaviours necessary for ongoing treatment success (Nation \& Woods, 1980; Quinn et al., 1996). In addition to behavioural strategies, anti-craving medications that facilitate extinction of cue reactivity (e.g., Kamboj et al., 2011; O’Brien, 2005) may be an appropriate adjunct to CBT counselling for those who have greater challenges managing urges to smoke.

However, our results should be interpreted with caution due to the following limitations. This study used a small sample, which included non-treatment seeking current smokers and recent ex-smokers. The small subsamples precluded exploring smoking status group differences. Thus, our results may not generalise to all recent quitters, or those motivated to quit smoking. Also, the procedures included implementation of massed cue exposure trials over one long session using a single urgeeliciting context. Such approaches may have limitations when translated to practice due to post extinction renewal or reinstatement effects (Collins \& Brandon, 2002; Conklin \& Tiffany, 2002) and may restrict the manipulation of reactivity compared to procedures that employ a greater variety of cues and contexts. Future studies could test more translatable and tailored models of cue exposure, perhaps initially assessing moderators or individual differences in reactivity (Karekla et al., 2015; Panayiotou et al., 2014; Unrod et al., 2014) affected by differences in conditioning history to identify the most salient cues to use with individual smokers in exposure sessions. Alternatively, clinicians could use spaced trial procedures across multiple sessions and contexts to improve generalisability of extinction learning. Despite the limitations, this study provides a first look into the influence of persistence on variability in smoking cue reactivity over time.

In conclusion, our results suggest that individual differences in persistence relate to abstinent smokers' urge reactivity in a high-risk context. Specifically, men with low persistence reported greater sustained urge reactivity across multiple cue exposure trials compared to men with high persistence in an analogue context that included smoking cues most immediately associated with smoking behaviour (e.g., the sight, smell and tactile cues related to cigarette smoking). That the data did not bear similar results among women is likely due to the limited reactivity (low urge) among women to the experimental procedures. More can be learned about how trait- like persistence may relate to the magnitude and duration of abstinent smokers' urge in situations that elicit strong urges. Because persistence is a modifiable individual difference characteristic, greater knowledge about a persistence - smoking urge association could guide targets of intervention tailoring to reduce relapse risk among abstinent smokers. To test the potential utility in translating this evidence to CET for nicotine dependence, future intervention research could explore the influence of boosting persistence as well as guiding coping skills during repeated exposure trials. Both the learned industriousness theory and associative learning theories suggest that such translation of cue exposure methods could facilitate extinction learning and promote effective compensatory coping for urge management, thereby improving the potential impact of behavioural intervention strategies in smoking cessation treatment.

\section{Acknowledgements}

The authors thank Jamie Dahm and James Kingham for data collection and management.

\section{Financial Support}

This research was supported by grants from the American Cancer Society Internal Research Grant mechanism distributed by the University of Pennsylvania Cancer Center and the Pennsylvania Department of Health Tobacco Fund distributed by Temple University to Collins. The funding sources were not involved in study design, collection, analysis, interpretation of data, writing this manuscript, or the decision to submit the manuscript for publication.

\section{Conflicts of Interest}

None.

\section{Ethical Standards}

The authors assert that all procedures contributing to this work comply with the ethical standards of the relevant national and institutional committees on human experimentation and with the Helsinki Declaration of 1975, as revised in 2008 .

\section{References}

Bagot, K. S., Heishman, S. J., \& Moolchan, E. T. (2007). Tobacco craving predicts lapse to smoking among adolescent smokers in cessation treatment. Nicotine \& Tobacco Research, 9(6), 647-652. https://doi.org/10.1080/ 14622200701365178.

Brandon, T. H., Herzog, T. A., Juliano, L. M., Irvin, J. E., Lazev, A. B., \& Simmons, V. N. (2003). Pretreatment task persistence predicts smoking cessation outcome. Journal of Abnormal Psychology, 112(3), 448-456. https://doi.org/10.1037/ 0021-843X.112.3.448. 
Brandon, T. H., Vidrine, J. I., \& Litvin, E. B. (2007). Relapse and relapse prevention. Annual Review of Clinical Psychology, 3, 257-284. https://doi.org/10.1146/annurev.clinpsy.3.022806. 091455.

Brown, R. A., Lejuez, C. W., Kahler, C. W., \& Strong, D. R. (2002). Distress tolerance and duration of past smoking cessation attempts. Journal of Abnormal Psychology, 111(1), 180-185. https://doi.org/10.1037/0021-843X.111.1.180.

Brown, R. A., Lejuez, C. W., Strong, D. R., Kahler, C. W., Zvolensky, M. J., Carpenter, L. L. et al. (2009). A prospective examination of distress tolerance and early smoking lapse in adult self-quitters. Nicotine and Tobacco Research, 11(5), 493-502. https://doi.org/10.1093/ntr/ntp041.

Cappelleri, J. C., Bushmakin, A. G., Baker, C. L., Merikle, E., Olufade, A. O., \& Gilbert, D. G. (2005). Revealing the multidimensional framework of the Minnesota nicotine withdrawal scale. Current Medical Research and Opinion, 21(5), 749-760. https://doi.org/10.1185/030079905X43712.

Cloninger, C. R., Przybeck, T. R., \& Svrakic, D. M. (1991). The tridimensional pPersonality questionnaire: U.S. normative data. Psychological Reports, 69(3 Pt 1), 1047-1057. https:// doi.org/10.2466/pr0.1991.69.3.1047.

Cloninger, C. R., Przybeck, T. R., Svrakic, D. M., \& Wetzel, R. D. (1994). The temperament and character inventory (TCI): A guide to its development and use. St. Louis: Washington University.

Cloninger, C. R., Svrakic, D. M., \& Przybeck, T. R. (1993). A psychobiological model of temperament and character. Archives of General Psychiatry, 50(12), 975-990. https://doi. org/10.1001/archpsyc.1993.01820240059008.

Collins, B. N., \& Brandon, T. H. (2002). Effects of extinction context and retrieval cues on alcohol cue reactivity among nonalcoholic drinkers. Journal of Consulting and Clinical Psychology, 70. https://doi.org/10.1037/0022-006X.70.2.390.

Collins, B. N., Ibrahim, J. K., Hovell, M., Tolley, N. M., Nair, U. S., Jaffe, K. et al. (2010). Residential smoking restrictions are not associated with reduced child SHS exposure in a baseline sample of low-income, urban African Americans. Health, 2(11), 1264-1271. https://doi.org/10.4236/ health.2010.211188.

Collins, B. N., Nair, U. S., \& Komaroff, E. (2011). Smoking cue reactivity across massed extinction trials: Negative affect and gender effects. Addictive Behaviors, 36(4), 308-314. https:// doi.org/10.1016/j.addbeh.2010.11.015

Conklin, C. A., \& Tiffany, S. T. (2002). Applying extinction research and theory to cue-exposure addiction treatments. Addiction. https://doi.org/10.1046/j.1360-0443.2002.00014. $\mathrm{x}$.

Crawford, J. R., \& Henry, J. D. (2004). The positive and negative affect schedule (PANAS): Construct validity, measurement properties and normative data in a large non-clinical sample. The British Journal of Clinical Psychology / the British Psychological Society, 43(Pt 3), 245-265. https://doi.org/10. 1348/0144665031752934.

Drummond, D. C., \& Glautier, S. (1994). A controlled trial of cue exposure treatment in alcohol dependence. Journal of Consulting and Clinical Psychology, 62(4), 809-817. https:// doi.org/10.1037/0022-006X.62.4.809.
Eisenberger, R., Michael Kuhlman, D., \& Cotterell, N. (1992). Effects of social values, effort training, and goal structure on task persistence. Journal of Research in Personality, 26(3), 258-272. https://doi.org/10.1016/0092-6566(92)90043-4.

Etter, J.-F. (2010). Smoking and Cloninger's temperament and character inventory. Nicotine \& Tobacco Research: Official Journal of the Society for Research on Nicotine and Tobacco, 12(9), 919-926. https://doi.org/10.1093/ntr/ntq116.

Germeroth, L. J., Carpenter, M. J., Baker, N. L., Froeliger, B., LaRowe, S. D., \& Saladin, M. E. (2017). Effect of a brief memory updating intervention on smoking behavior: A randomized clinical trial. JAMA Psychiatry, 74(3), 214-223.

Hartwell, K. J., Hanlon, C. A., Li, X., Borckardt, J. J., Canterberry, M., Prisciandaro, J. J. et al. (2016). Individualized real-time fMRI neurofeedback to attenuate craving in nicotine-dependent smokers. Journal of Psychiatry \& Neuroscience: JPN, 41(1), 48-55. https://doi.org/10.1503/JPN.140200.

Hughes, J. R., \& Hatsukami, D. (1986). Signs and symptoms of tobacco withdrawal. Archives of General Psychiatry, 43. https: //doi.org/10.1001/archpsyc.1986.01800030107013.

Kalman, D., Hoskinson, R., Sambamoorthi, U., \& Garvey, A. J. (2010). A prospective study of persistence in the prediction of smoking cessation outcome: Results from a randomized clinical trial. Addictive Behaviors, 35(2), 179-182. https://doi.org/10.1016/j.addbeh.2009.09.017.

Kamboj, S. K., Massey-Chase, R., Rodney, L., Das, R., Almahdi, B., Curran, H. V. et al. (2011). Changes in cue reactivity and attentional bias following experimental cue exposure and response prevention: A laboratory study of the effects of Dcycloserine in heavy drinkers. Psychopharmacology, 217(1), 25-37. https://doi.org/10.1007/s00213-011-2254-z.

Karekla, M., Champi, S. C., Panayiotou, G., \& Collins, B. N. (2015). Gender moderates effects of frustration tolerance on smoking urges. In Symposium Presented at the European Health Psychology Society Conference. Limmisol, Cyprus.

Kavanagh, D. J., Andrade, J., \& May, J. (2005). Imaginary relish and exquisite torture: The elaborated intrusion theory of desire. Psychological Review, 112(2), 446-467. https://doi.org/ 10.1037/0033-295X.112.2.446.

Lam, C. Y., Robinson, J. D., Versace, F., Minnix, J. A., Cui, Y., Carter, B. L. et al. (2012). Affective reactivity during smoking cessation of never-quitters as compared with that of abstainers, relapsers, and continuing smokers. Experimental and Clinical Psychopharmacology, 20(2), 139-150. https: //doi.org/10.1037/a0026109.

Leyro, T. M., Zvolensky, M. J., \& Bernstein, A. (2010). Distress tolerance and psychopathological symptoms and disorders: a review of the empirical literature among adults. Psychological Bulletin, 136(4), 576. https://doi.org/10.1037\% $2 \mathrm{Fa} 0019712$.

Lejuez, C. W., Kahler, C. W., \& Brown, R. A. (2003). A modified computer version of the paced auditory serial addition task (PASAT) as a laboratory-based stressor. The Behavior Therapist, 26(4), 290-293. https://doi.org/10.1016/j.beth.2006.08. 006. 
Littel, R., Stroup, W., Milliken, G., Wolfinger, R., \& Schabenberger, O. (2006). SAS for mixed models. Cary, NC: SAS Institute, Inc.

Nation, J. R., \& Woods, D. J. (1980). Persistence: The role of partial reinforcement in psychotherapy. Journal of Experimental Psychology, 109(2), 175-207. https://doi.org/10. 1037/0096-3445.109.2.175.

O'Brien, C. P. (2005). Anticraving medications for relapse prevention: A possible new class of psychoactive medications. American Journal of Psychiatry. https://doi.org/10. 1176/appi.ajp.162.8.1423.

O’Connell, K. A., Shiffman, S., \& DeCarlo, L. T. (2011). Does extinction of responses to cigarette cues occur during smoking cessation? Addiction, 106(2), 410-417. https://doi. org/10.1111/j.1360-0443.2010.03172.x.

Orleans, C. T., Rimer, B. K., Cristinzio, S., Keintz, M. K., \& Fleisher, L. (1991). A national survey of older smokers: Treatment needs of a growing population. Health Psychology: Official Journal of the Division of Health Psychology, American Psychological Association, 10(5), 343-351. https: //doi.org/10.1037//0278-6133.10.5.343.

Panayiotou, G., Karekla, M., Champi, S. C., \& Collins, B. N. (2014). Smoking urges after a stressor task are mediated by negative emotion. Psychophysiology, 51, S32-S32.

Payne, T. J., Smith, P. O., Adams, S. G., \& Diefenbach, L. (2006). Pretreatment cue reactivity predicts end-oftreatment smoking. Addictive Behaviors, 31(4), 702-710. https://doi.org/10.1016/J.ADDBEH.2005.05.053.

Perkins, K. A. (2009). Does smoking cue-induced craving tell us anything important about nicotine dependence? Addiction, 104(10), 1610-1616. https://doi.org/10.1111/j.1360-0443. 2009.02550.x.

Perkins, K. A. (2012). Subjective reactivity to smoking cues as a predictor of quitting success. Nicotine \& Tobacco Research, 14(4), 383-387. https://doi.org/10.1093/ntr/ntr229.

Perkins, K. A., Donny, E., \& Caggiula, A. R. (1999). Sex differences in nicotine effects and self-administration: Review of human and animal evidence. Nicotine \& Tobacco Research, 1(4), 301-315. Retrieved from http://www.ncbi.nlm.nih. gov/entrez/query.fcgi? $c m d=$ Retrieve $\& \mathrm{db}=\mathrm{PubMed} \& \mathrm{dopt}=$ Citation\&list_uids $=11072427$.

Perkins, K. A., Epstein, L. H., Grobe, J., \& Fonte, C. (1994). Tobacco abstinence, smoking cues, and the reinforcing value of smoking. Pharmacology, Biochemistry, and Behavior, 47(1), 107-112. https://doi.org/10.1016/0091-3057(94)90118-X.

Quinn, E. P., Brandon, T. H., \& Copeland, A. L. (1996). Is task persistence related to smoking and substance abuse? The application of learned industriousness theory to addictive behaviors. Experimental and Clinical Psychopharmacology. https://doi.org/10.1037/1064-1297.4.2.186.

Raudenbush, S. W., \& Bryk, A.S. (2002). Hierarchical linear models: Applications and data analysis methods. Advanced Quantitative Techniques in the Social Sciences, 1, 160 202.

Shadel, W. G., Niaura, R., Abrams, D. B., Goldstein, M. G., Rohsenow, D. J., Sirota, A. D. et al. (1998). Scripted imagery manipulations and smoking cue reactivity in a clinical sample of self-quitters. Experimental and Clinical Psychopharmacology, 6(2), 179-186. https://doi.org/10. 1037/1064-1297.6.2.179.

Shiffman, S. (1991). Refining models of dependence: Variations across persons and situations. Addiction, 86(5), 611-615. https://doi.org/10.1111/j.1360-0443.1991.tb01817.x.

Steinberg, M. L., Williams, J. M., Gandhi, K. K., Foulds, J., \& Brandon, T. H. (2010). Lower task persistence in smokers with schizophrenia as compared to non-psychiatric control smokers. Psychology of Addictive Behaviors: Journal of the Society of Psychologists in Addictive Behaviors, 24(4), 724-729. https://doi.org/10.1037/a0020972.

Steinberg, M. L., Williams, J. M., Gandhi, K. K., Foulds, J., Epstein, E. E., \& Brandon, T. H. (2012). Task persistence predicts smoking cessation in smokers with and without schizophrenia. Psychology of Addictive Behaviors. https://doi. org/10.1037/a0028375.

Tiffany, S. T. (1990). A cognitive model of drug urges and druguse behavior: Role of automatic and nonautomatic processes. Psychological Review, 97(2), 147-168. https://doi.org/ 10.1037/0033-295X.97.2.147.

Tiffany, S. T., \& Wray, J. (2009). The continuing conundrum of craving. Addiction, 104(10), 1618-1619. https://doi.org/10. 1111/j.1360-0443.2009.02588.x.

Unrod, M., Drobes, D. J., Stasiewicz, P. R., Ditre, J. W., Heckman, B., Miller, R. R. et al. (2014). Decline in cueprovoked craving during cue exposure therapy for smoking cessation. Nicotine \& Tobacco Research, 16(3), 306-315. https://doi.org/10.1093/ntr/ntt145.

Ussher, M, Beard, E, Abikoye, O, Hajek, P, \& West, R. (2013). Urge to smoke over 52 weeks of abstinence. Psychopharmacology, 226, 83-89.

Waters, A., Shiffman, S., Sayette, M., Paty, J., Gwaltney, C., \& Balabanis, M. (2004). Cue-provoked craving and nicotine replacement therapy in smoking cessation. Journal of Consulting and Clinical Psychology, 72(6), 11361143.

Watson, D., Clark, L. A., \& Tellegen, A. (1988a). Development and validation of brief measures of positive and negative affect: The PANAS scales. Journal of Personality and Social Psychology, 54(6), 1063-1070. https://doi.org/10.1037/ 0022-3514.54.6.1063.

Watson, D., Clark, L. A., \& Tellegen, A. (1988b). Positive and negative affect schedule (PANAS). Journal of Personality and Social Psychology, 54, 1063-1070. https://doi.org/10.1037/ t03592-000.

West, R., \& Ussher, M. (2010). Is the ten-item questionnaire of smoking urges (QSU-brief) more sensitive to abstinence than shorter craving measures? Psychopharmacology, 208(3), 427-432. https://doi.org/10.1007/s00213-009-1742-x.

World Health Organization. (2015). Tobacco fact sheet number 339. Retrieved June 5, 2015, from http://www.who.int/ mediacentre/factsheets/fs339/en/.

Wray, J. M., Gass, J. C., \& Tiffany, S. T. (2013). A systematic review of the relationships between craving and smoking cessation. Nicotine \& Tobacco Research, 15(7), 1167-1182. https://doi.org/10.1093/ntr/nts268. 
Xue, Y.X., Deng, J. H., Chen, Y. Y., Zhang, L. B., Wu, P., Huang, G. D. et al. (2017). Effect of selective inhibition of reactivated nicotine-associated memories with propranolol on nicotine craving. JAMA Psychiatry, 74(3), 224232.
Zilberman, M. L., Tavares, H., \& El-Guebaly, N. (2003). Relationship between craving and personality in treatmentseeking women with substance-related disorders. BMC Psychiatry, 3(1), 1. https://doi.org/10.1186/1471244X-3-1. 